\title{
Salinity measurements from pop-up archival transmitting (PAT) tags and their application to geolocation estimation for Atlantic tarpon
}

\author{
Jiangang Luo ${ }^{1, *}$, Jerald S. Ault ${ }^{1}$, Michael F. Larkin ${ }^{1}$, Luiz R. Barbieri ${ }^{2}$ \\ ${ }^{1}$ University of Miami Rosenstiel School of Marine and Atmospheric Sciences (RSMAS), Division of Marine Biology and \\ Fisheries, 4600 Rickenbacker Causeway, Miami, Florida 33149, USA \\ ${ }^{2}$ Florida Fish \& Wildlife Conservation Commission, Florida Fish \& Wildlife Research Institute, 100 8th Avenue SE, \\ St. Petersburg, Florida 33701, USA
}

\begin{abstract}
A new wet/dry sensor was developed by the satellite-based pop-up archival transmitting (PAT) tag manufacturer to determine the wet and dry status of a tag, designed to indicate whether or not to initiate uplink transmissions to overhead satellites to extend tag battery life. We discovered that the wet/dry sensor can also be used to measure the salinity of coastal waters after we recovered a PAT tag showing oscillating readings of wet/dry sensor values that mimicked tidal cycles. We conducted a calibration experiment on 6 PAT tags to evaluate the stability, resolution, and accuracy of the sensor to obtain salinity measurements. Our results indicated that the wet/dry sensor was stable, and the resolution and accuracy of the sensor were good at low salinities $(<20$ psu), but relatively poor at high salinities. We then provide an example showing how the salinity information can be used to improve geolocation estimation for a large coastal marine fish, the Atlantic tarpon Megalops atlanticus.
\end{abstract}

KEY WORDS: Salinity $\cdot$ PAT tags $\cdot$ Wet/dry sensor $\cdot$ Geolocation $\cdot$ Atlantic tarpon

\section{INTRODUCTION}

Over the past decade, satellite-based pop-up archival transmitting (PAT) tag technologies have facilitated an improved understanding of migrations, behavior patterns and environmental preferences (i.e. ocean 'habitat' utilization) for a number of large marine fishes including: tunas (Block et al. 1998a,b, 2001, 2005, Lutcavage et al. 1999); billfish (Sedberry \& Loefer 2001, Graves et al. 2002, Kerstetter et al. 2003, Luo et al. 2006, Prince \& Goodyear 2006); sharks (Boustany et al. 2002, Loefer et al. 2005); and ocean sunfish Mola mola (Seitz et al. 2002). PAT tags store ambient light-level data, which are transmitted and used to estimate longitude and latitude (Wilson et al. 1992, Hill 1994, Hill \& Braun 2001, Musyl et al. 2001). However, the best light-level geolocation estimates are only as accurate as \pm 0.2 to \pm 0.9 degrees in longitude and \pm 0.6 to \pm 4.4 degrees in latitude (e.g.
Welch \& Eveson 1999, 2001, Musyl et al. 2001, Schaefer $\&$ Fuller 2002). In recent years, researchers have used sea surface temperatures (SST) to improve the accuracy of light-level geolocation estimates (Domeier et al. 2004, Teo et al. 2004, Nielsen et al. 2006). However the SST method is only useful for areas where there is a significant temperature gradient (Domeier et al. 2004, Teo et al. 2004, Nielsen et al. 2006); moreover, nearshore satellite SST values are often far less accurate than those for the open ocean (Pearce at al. 2006).

In 2001, we began a research program using the PAT technology for a large coastal marine fish, Atlantic tarpon Megalops atlanticus, with the goal to monitor and assess seasonal migration patterns and stock connectivity and to define vertical- and thermo-habitat utilization in the western Atlantic Ocean and Gulf of Mexico (Luo et al. 2008). However, geolocation estimates made from light-level data were typically very 
poor, due to the relatively high turbidity of coastal ocean waters. In 2006, we initiated use of a new generation of MK-10 PAT tags, manufactured by Wildlife Computers (www.wildlifecomputers.com) and equipped with a wet/dry sensor. In the course of our studies, we noted some interesting features of the recorded wet/dry sensor values that we obtained from a recovered PAT tag (Fig. 1b). We suspected that the variations of wet/dry sensor values were related to the salinity of the coastal ocean environment that the tarpon experienced during movements and migrations. Therefore, we conducted an experiment to calibrate empirical wet/dry sensor values recorded by the tag and compared these to precise salinity measurements obtained from a CTD instrument. In this article, we present the results from those experiments and discuss the potential usefulness of the salinity measurements in both refining light-level geolocation estimates and defining habitat utilization patterns for coastal fishes.

\section{MATERIALS AND METHODS}

Pop-up archival transmitting (PAT) tag. The PAT tag is designed to be attached to a study animal via a tether (Fig. 2). It collects data during the deployment period, and then at a pre-set date and time it pops up (releases from the study animal) and transmits archived data via the Argos satellite system. The PAT tag used in the present study is a new product (MK10) from Wildlife Computers with a new wet/dry sensor, and detailed technical specifications for the tag can be found at www. wildlifecomputers.com. The new wet/dry sensor located at the base of the antenna provides 8-bit analogto-digital conversion for measuring resistance between the sensor and the base metal ring positioned below the float, which determines the wet and/or dry (i.e. in/out of water) status of the tag. Outputs relative to wet/dry sensor values (WDSV) are scaled from 0 to 255 (8-bit). Each Argos transmission begins only when the wet/ dry sensor reads 'dry', which ensures the antenna is out of the water before initiating a transmission.

Calibration experiment. We conducted a calibration experiment by placing a conductivity, temperature, and depth (CTD) instrument (Sea-Bird SBE19plus SEACAT profiler) with 6 MK10 PAT tags in a $400 \mathrm{l}$ glass aquarium at the Rosenstiel School of Marine and Atmospheric Science (RSMAS) ship dock located on Virginia Key, Florida. We started the experiment by filling the aquarium with full-strength seawater. The salinity of seawater from the ocean was $35.01 \mathrm{psu}$ (practical salinity units) and the temperature was $24.2^{\circ} \mathrm{C}$. During the next $2 \mathrm{~h}$ we diluted the seawater with fresh tap water by removing about $25 \%$ of water in the aquarium every $5 \mathrm{~min}$, and placed the tags in tap water at the end (Fig. 3a). Both CTD and MK10 tags were set to record at $1 \mathrm{~s}$ intervals.

There was some noise associated with WDSV (Fig. 4a); therefore, we applied a \pm 10 s moving average filter to remove the noise (Fig. 4b) before any further

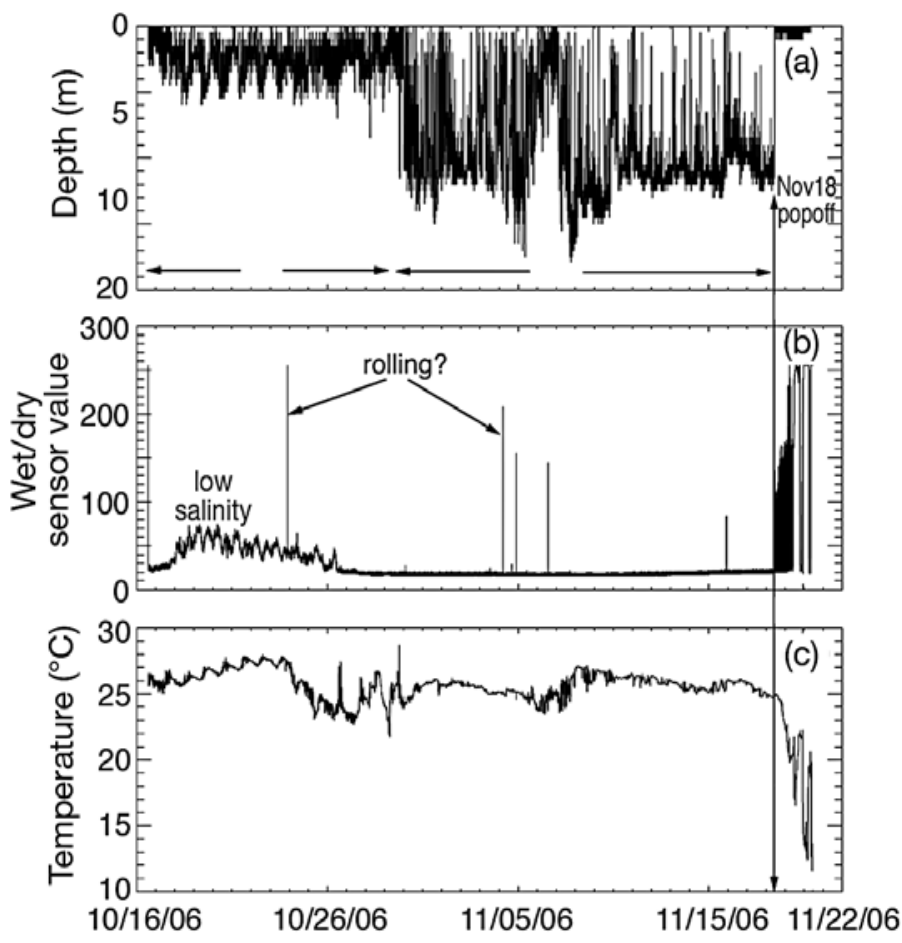

Fig. 1. Various ocean environment measurements recorded by an MK10 PAT tag that was deployed on 16 October 2006 and recovered on 21 November 2006: (a) depth, (b) wet/dry sensor values (WDSV) and (c) water temperature

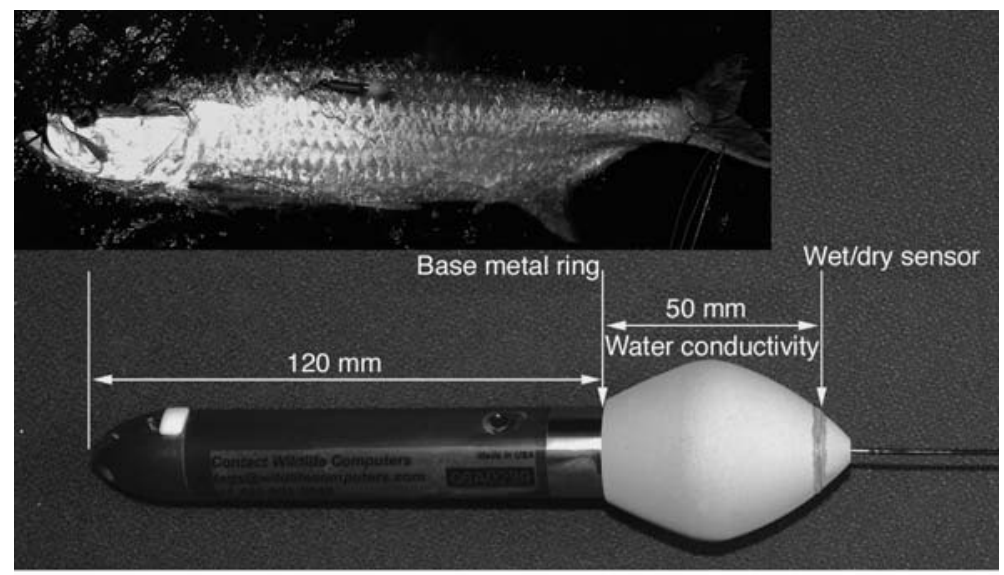

Fig. 2. Wet/dry sensor location and dimensions of MK10 PAT tags, and a tagged tarpon just before release (inset) 

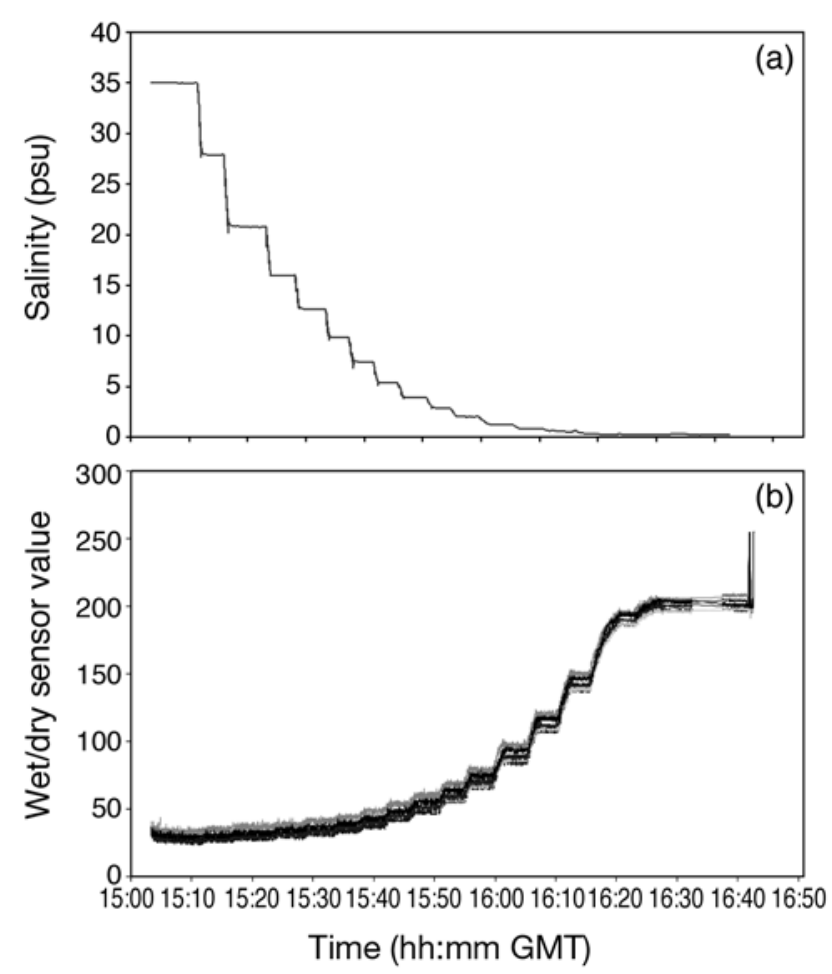

Fig. 3. (a) Salinity (psu) recorded by a CTD (Sea-Bird SBE19plus SEACAT profiler) during the calibration experiment and (b) WDSV (relative value scale to 8-bit) recorded by 6 different MK10 PAT tags used in the salinity calibration experiment

analysis. Since WDSV was a measure of relative conductivity, which itself is a function of salinity, temperature and depth, we fitted conductivity $(C)$ measurements from the CTD as a function of WDSV using a natural log-transformed fourth-order polynomial model:

$$
\operatorname{Ln}\left(C_{i}\right)=b_{0}+b_{1} X_{i}+b_{2} X_{i}^{2}+b_{3} X_{i}^{3}+b_{3} X_{i}^{4}+\xi_{i}
$$

where $X_{i}=\mathrm{Ln}(\mathrm{FV} / 25), \mathrm{FV}$ is the filtered WDSV and $b_{0}$, $b_{1}, b_{2}, b_{3}$ and $b_{4}$, are parameters of the multiple regression model that were estimated using interactive data language (IDL) following the forward methods in Neter et al. (1996). We calculated salinity according to the algorithm published in Lewis (1980).
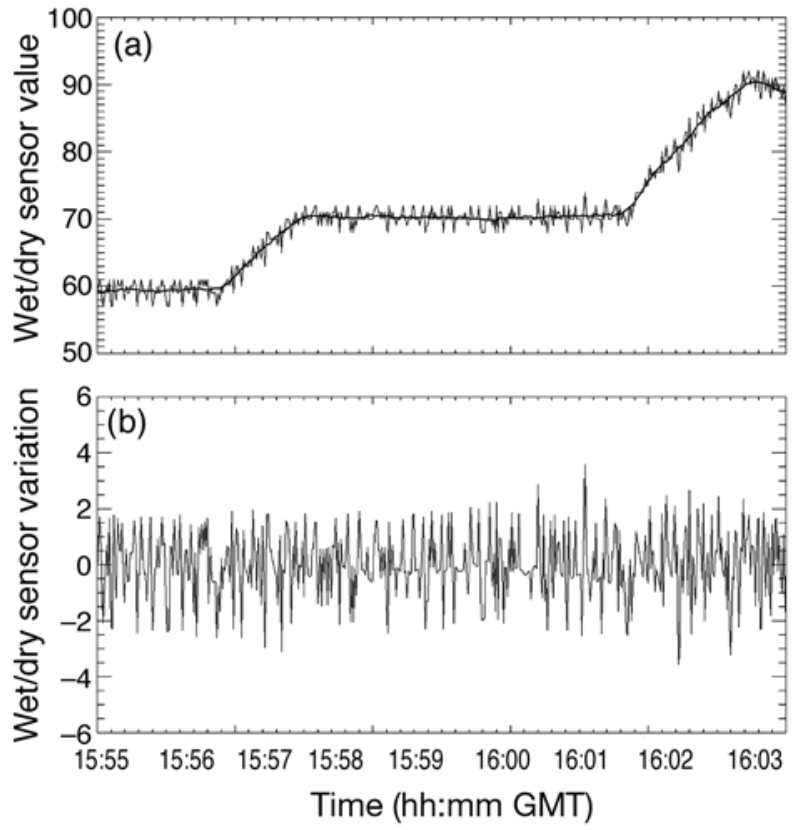

Fig. 4. Observed variability of the wet/dry sensor: (a) raw WDSV (thin line) and the $\pm 10 \mathrm{~s}$ moving average (FV, thick line) and (b) the residuals of WDSV, i.e. the difference between the raw and moving average

\section{RESULTS}

\section{Empirical salinity calibrations}

The WDSV from all 6 tags responded well to the changes in salinity (Fig. 3b). The noise associated with the unfiltered WDSV is about 2 units on the 8-bit scale (Fig. 4), with a standard deviation about 1 unit for the entire range (i.e. 20 to 210 ) tested in the present study. The statistical filter effectively removed the noise (Fig. 4). There were small differences between tags, which were expected because of minor differences in the physical properties between the tags (Table 1). Differences between tags were especially prominent in regions of high conductivity (Fig. 5). Resolution and accuracy of the salinity measurements were limited by

Table 1. Estimated multivariate model parameters for Eq. (1) for the 6 MK 10 PAT tags used in the empirical salinity calibration experiment

\begin{tabular}{|lccccccc|}
\hline Parameter & Tag 53 & Tag 55 & Tag 56 & Tag 57 & Tag 58 & Tag 59 & Average \\
\hline$b_{0}$ & -1.39982 & -1.46352 & -1.46243 & -1.55246 & -1.50499 & -1.46721 & -1.47507 \\
$b_{1}$ & -3.49967 & -4.11123 & -3.36197 & -3.80681 & -3.85735 & -3.87202 & -3.75151 \\
$b_{2}$ & -2.03294 & -2.81568 & -1.57900 & -2.29241 & -2.46922 & -2.38851 & -2.26296 \\
$b_{3}$ & -0.83965 & -1.31663 & -0.42810 & -0.85974 & -1.04786 & -0.99126 & -0.91387 \\
$b_{4}$ & -0.07121 & -0.14154 & 0.02906 & -0.04359 & -0.10929 & -0.08589 & -0.07041 \\
$\mathrm{r}$ & 0.9990 & 0.9999 & 0.9999 & 0.9999 & 0.9991 & 0.9991 & 0.9995 \\
\hline
\end{tabular}



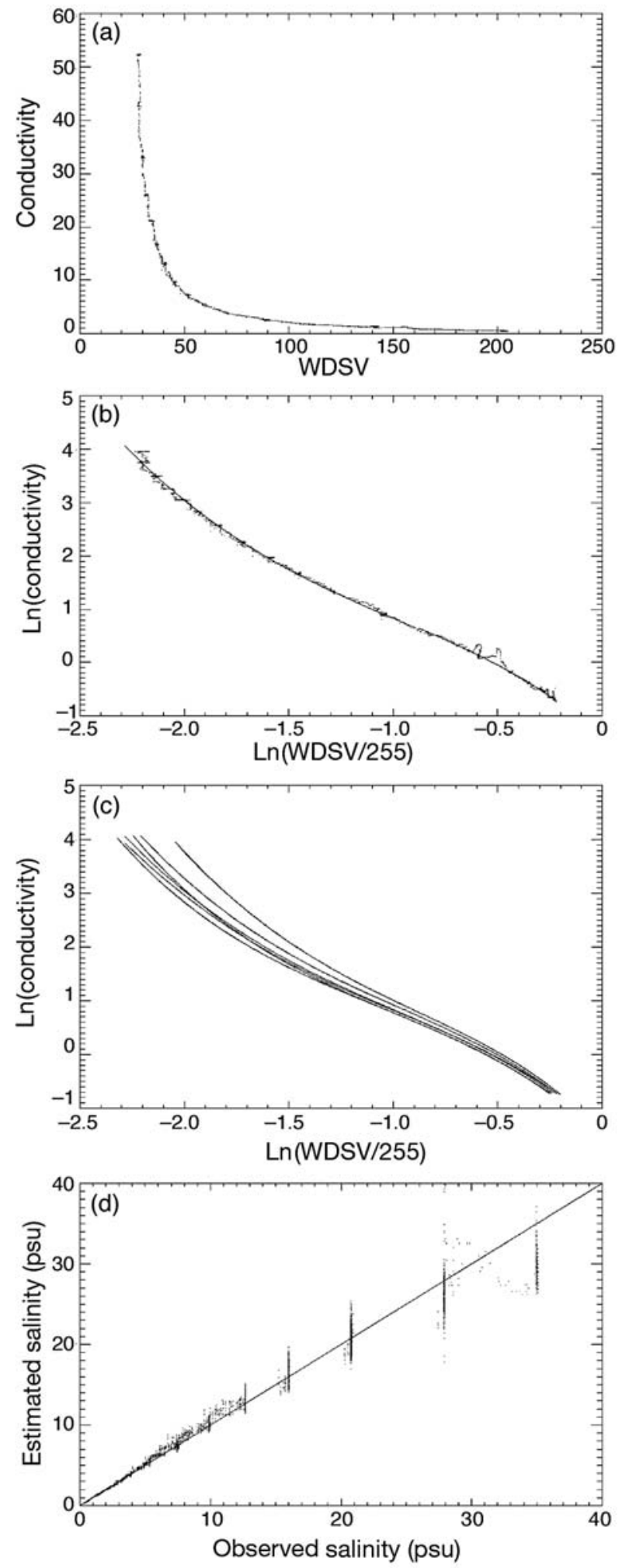

Fig. 5. Results of the salinity calibration experiment: (a) conductivity recorded by CTD as a function of WDSV from PAT Tag 53, (b) natural log-transformed conductivity (dots) as a function of Ln(WDSV/255) in comparison to a multivariate linear model fit (line) for PAT Tag 53, (c) model fits for all 6 PAT tags and (d) estimated salinity as a function of observed salinity the properties of the sensor and by its 8-bit analog-todigital conversion scheme. The 8-bit data conversion scaled measurements into 256 integers (0 to 255). Therefore, measurement resolution was 1 integer unit. Because of the non-linear relationship between conductivity and WDSV (Fig. 5a), the resolution of salinity measurements decreased exponentially as a function of salinity (Fig. 6a,b). For example, at salinity 5 psu the resolution is about $0.3 \mathrm{psu}(6 \%)$, whereas at salinity $20 \mathrm{psu}$ the resolution is about $2.8 \mathrm{psu}(14 \%)$, and at salinity $30 \mathrm{psu}$ the resolution is about $5.5 \mathrm{psu}(18 \%)$. As a result of decreased resolution at higher salinities, the accuracy of the salinity measurement also decreased (Fig. 6c).

\section{Field trials}

On 16 October 2006, we captured a $50 \mathrm{~kg}$ tarpon Megalops atlanticus in the St. Lucie River, Florida, and
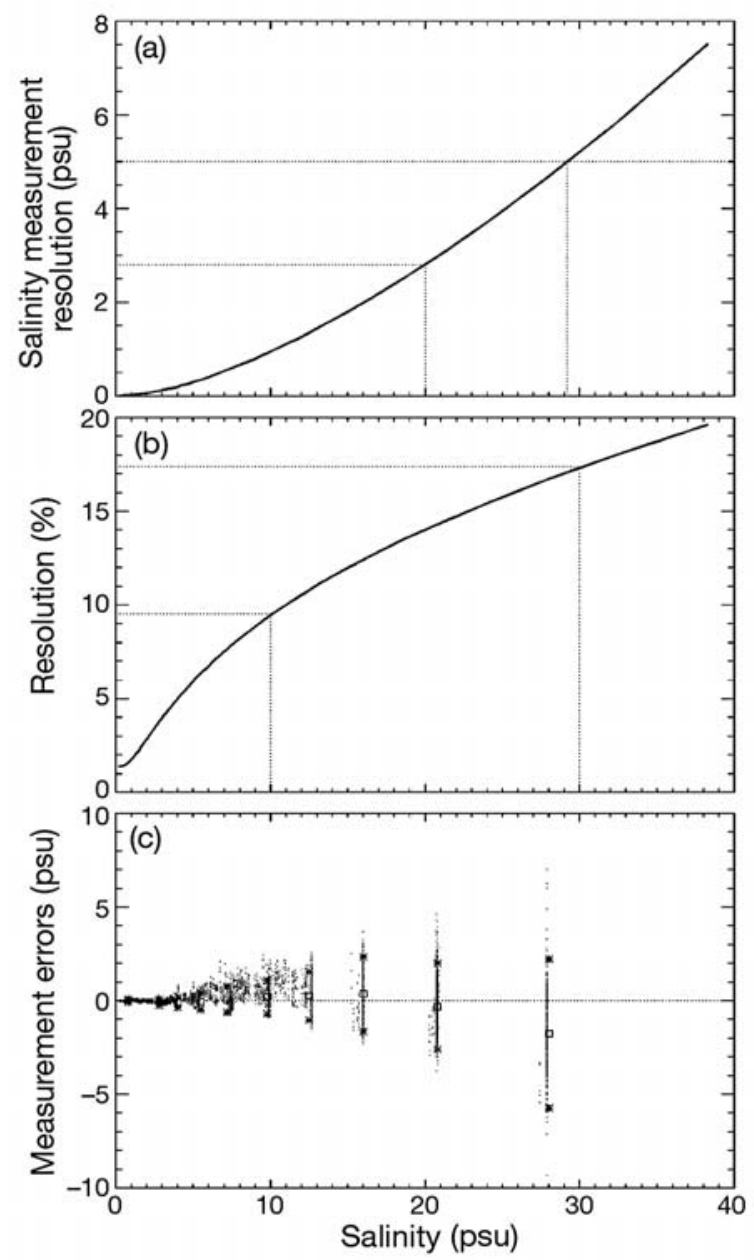

Fig. 6. Salinity measurement resolution and accuracy by wet/ dry sensors: (a) absolute resolution in psu, (b) relative resolution $(\%)$ and (c) absolute accuracy 
tagged it with a MK10 PAT tag (Fig. 2). The tag was pre-set to record depth, temperature, light level and WDSV at $10 \mathrm{~s}$ intervals. The tag subsequently poppedoff and drifted into Fort Pierce Inlet (Fig. 7) on 19 November 2006. We were able to physically recover the tag with the assistance of an Argos receiver (TSUR400 Argos receiver from Telonics, www.telonics.com), and subsequently to retrieve all the archived data. To these data we applied the results from our empirical calibration study. First, we estimated the conductivities from WDSV (Fig. 8a); then, we used the conductivity, temperature and depth (CTD) to estimate the salinity based on the practical salinity scale equations (Fig. 8d). Light-level geolocation data were initially processed using global positioning software WC-GPE (Wildlife Computers). We then applied a SST-corrected Kalman filter (Nielsen et al. 2006) to the light-level-derived locations.

The distance between the point of release for the PAT-tagged tarpon and the location where the tag was found was only about $35 \mathrm{~km}$ (20 miles), with a longitudinal difference of only about $0.1^{\circ}$. The geolocation information derived from light-level data and Kalman filter processing are within $\pm 1^{\circ}$ of deployment and pop-up locations for both longitude and latitude (Fig. 7a); these were not useful for determining the location of this fish for its time at liberty. Estimated salinity values ranged from 2 to 35 psu (Fig. 8d), indicating that the tarpon had traveled to the upstream end of the St. Lucie River. We obtained water-quality information for the St. Lucie River from monitoring stations operated by the Florida Oceanographic Society, which produces weekly reports on the condition of the river system and includes salinity and temperature data from different parts of the river (Table 2). From 17 to 25 October 2006, the tag recorded salinity data ranging from 2 to $10 \mathrm{psu}$, which had an apparent cyclical pattern that perfectly matched with the cyclical tidal patterns of the St. Lucie River (Fig. 8d). Two areas (1 and 4 ) in the system had salinities consistently $<10$ psu (Table 2, Fig. 7b). Area 4 was a small tributary, with depths $<3 \mathrm{~m}$, but the tag recorded maximum depths $>5 \mathrm{~m}$. Therefore, the only area that had both salinity and depths matching those recorded on the tag was

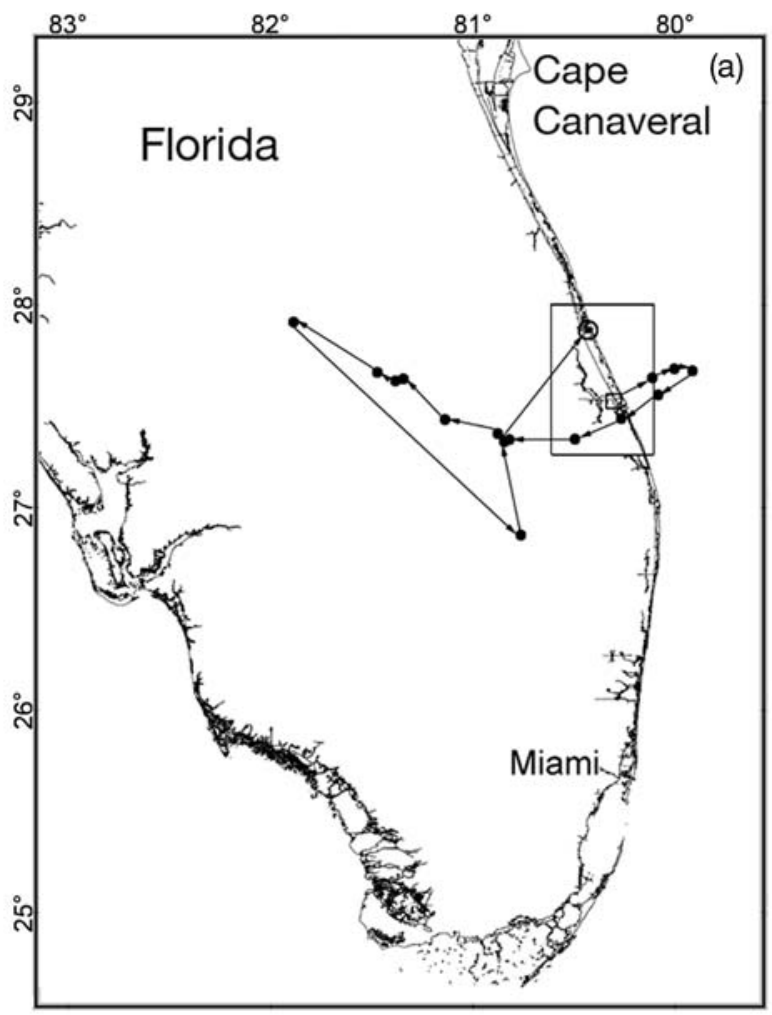

Fig. 7. (a) Map of southeastern Florida and geolocations (solid dots) estimated from light level and a sea surface temperature-corrected Kalman filter, and tag deployment (open square) and tag recovery (open circle) locations. (b) A close up map from St. Lucie Inlet to Ft. Pierce Inlet and the probable track of the tarpon Magalops atlanticus based on salinity, depth and water transparency. Nine sub-areas from Table 2 are each marked with numbers ranging from 1 to 9

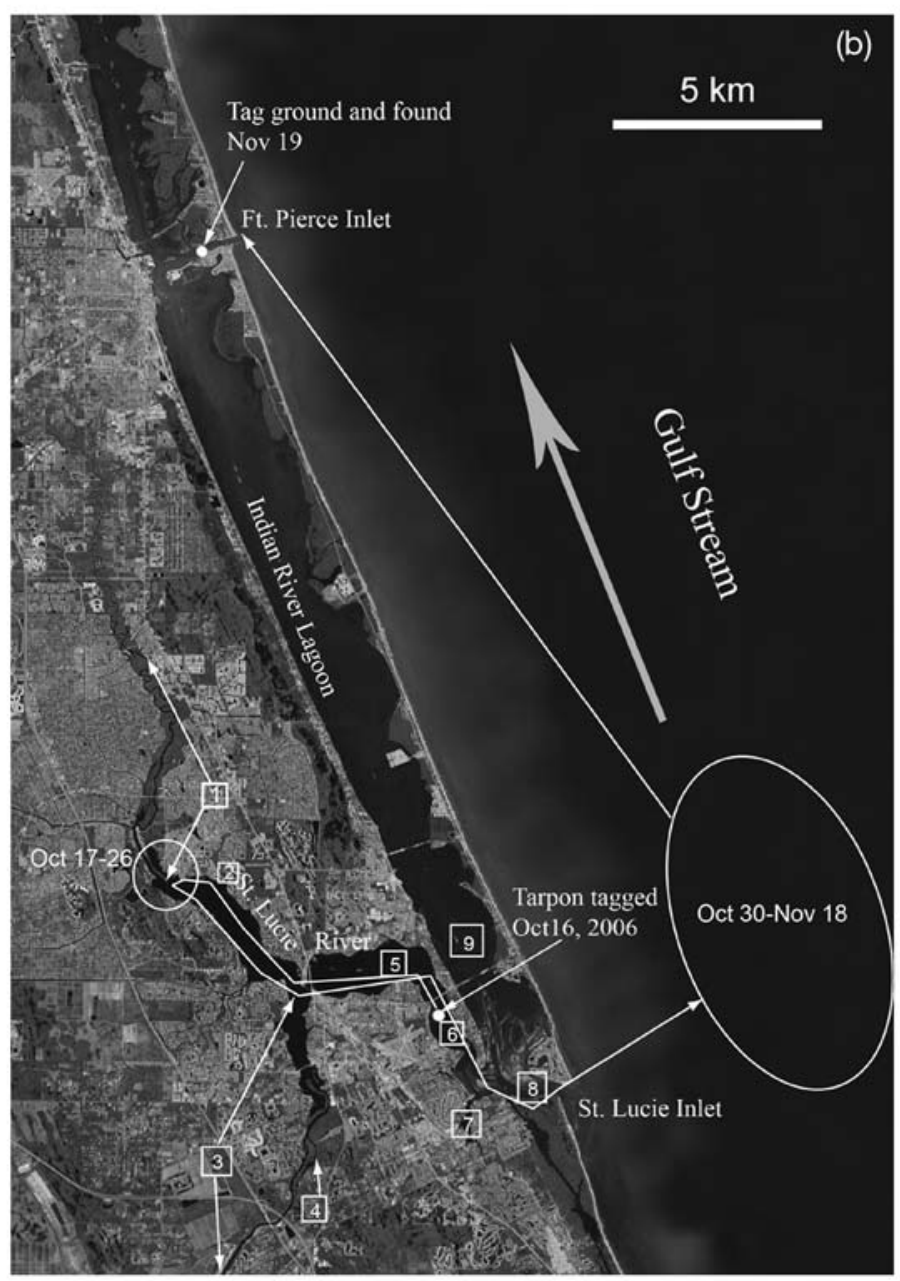



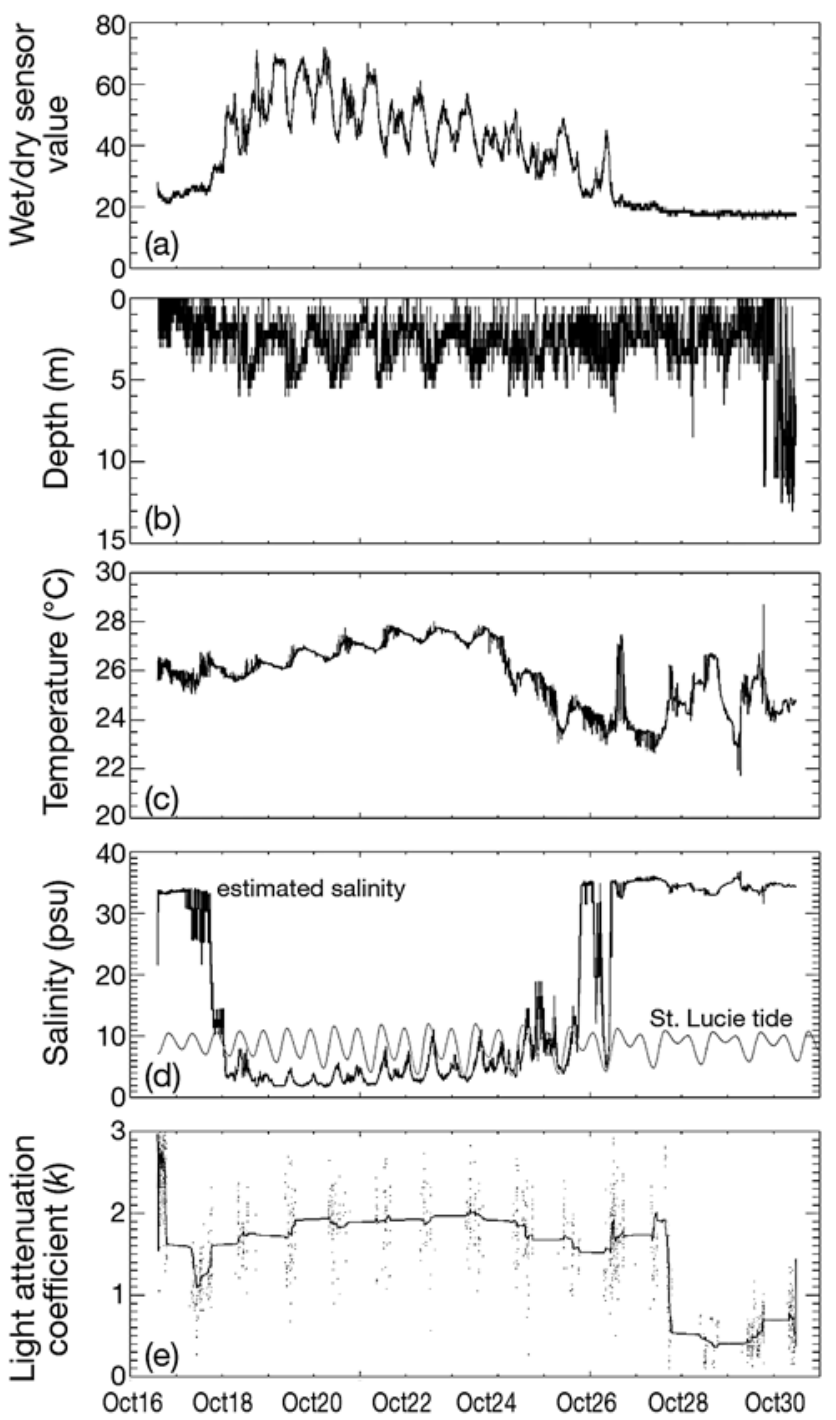

Fig. 8. Environmental data recorded by the MK10 PAT tag sensors for the period of 16 to 30 October 2006: (a) WDSV, (b) depth, (c) temperature, (d) estimated salinity and tide phase in St. Lucie River and (e) light-attenuation coefficient derived from light-level data
Area 1 (Fig. 7b). Furthermore, because the cyclical pattern of salinity exactly followed the tidal pattern, we were able to narrow the location of the fish to the lower portion of Area 1. On 26 October, the tarpon apparently started to move out of the river, following passage of a cold front when temperatures were observed to have decreased (Fig. 8c). On 27 October, the tarpon moved out of the St. Lucie Inlet system to the Atlantic Ocean, as indicated by the low light attenuation coefficients (Fig. 8e) and warmer water temperatures (Fig. 8c), and had moved further offshore by 30 October, as indicated by the relatively deep water depth profiles (Fig. 8b). The tarpon stayed offshore for the remainder of deployment period, and the tag apparently poppedoff on 18 November, while the fish was at $15 \mathrm{~m}$ depth as indicated by the sudden change of depth and WDSV (Fig. 1a, b). The tag then was carried by ocean currents and winds into the Fort Pierce Inlet, Florida, where it was found on 19 November.

\section{DISCUSSION}

This study showed that knowledge of the salinities that a fish encounters in coastal waters during tag deployment can be used to help refine its geographic locations (geolocations). For this tag, geolocations based on light-level data and a SST-corrected Kalman filter are within $\pm 1^{\circ}$ longitude and latitude of both deployment and pop-up locations (Fig. 7a), which could be considered fairly good estimates for relatively large geographic areas (Teo et al. 2004, Nielsen et al. 2006), but would not help us in this study. Without the availability of the additional information concerning salinity, we would have only been able to use lightattenuation and depth data to determine location, which placed the tarpon Megalops atlanticus in the lower St. Lucie River, where it was tagged and stayed for the period from 16 to 26 October. The PAT-tagged tarpon then left the river for the ocean between 27 and

Table 2. Weekly salinity and water temperatures observed in the St. Lucie River, Florida (source: Florida Oceanographic Society, www.floridaoceanograghic.org/water.htm)

\begin{tabular}{|c|c|c|c|c|c|c|c|c|c|}
\hline \multirow{2}{*}{$\begin{array}{l}\text { Area } \\
\text { ID }\end{array}$} & \multirow{2}{*}{ Location } & \multicolumn{2}{|c|}{-11 Oct -} & \multicolumn{2}{|c|}{-18 Oct -} & \multicolumn{2}{|c|}{-25 Oct -} & \multirow{2}{*}{$\overline{\text { Salinity }}$} & \multirow{2}{*}{$\begin{array}{l}1 \mathrm{Nov} \\
\text { Temp. }\left({ }^{\circ} \mathrm{C}\right)\end{array}$} \\
\hline & & Salinity & Temp. $\left({ }^{\circ} \mathrm{C}\right)$ & Salinity & Temp. $\left({ }^{\circ} \mathrm{C}\right)$ & Salinity & Temp. $\left({ }^{\circ} \mathrm{C}\right)$ & & \\
\hline 1 & Winding North Fork & 3.3 & 26.1 & 3.0 & 23.9 & 3.0 & 26.1 & 3.0 & 22.2 \\
\hline 2 & North Fork & 11.5 & 26.1 & 17.5 & 26.1 & 17.0 & 27.2 & 20.0 & 23.3 \\
\hline 3 & South Fork & 11.5 & 24.4 & 18.5 & 25.0 & 19.5 & 27.2 & 22.0 & 22.8 \\
\hline 4 & Winding South Fork & 0.8 & 27.2 & 2.8 & 27.2 & 3.6 & 27.2 & 4.0 & 23.9 \\
\hline 5 & Wide Middle River & 20.0 & 26.1 & 23.0 & 24.4 & 24.5 & 23.9 & 26.0 & 24.4 \\
\hline 6 & Narrow Middle River & 29.0 & 28.3 & 30.5 & 27.2 & 30.0 & 27.8 & 30.0 & 24.4 \\
\hline 7 & Manatee Pocket & 30.5 & 26.1 & 30.6 & 26.1 & 33.1 & 22.2 & 31.9 & 24.4 \\
\hline 8 & Inlet Area & 35.6 & 27.2 & 33.5 & 25.0 & 35.8 & 27.8 & 35.5 & 23.9 \\
\hline 9 & Indian River Lagoon & 32.5 & 25.0 & 34.0 & 25.0 & 35.0 & 26.1 & 36.5 & 21.7 \\
\hline
\end{tabular}


30 October, as indicated by low light-attenuation coefficients (Fig. 8e) and deeper depths (Fig. 1a). The additional salinity data enabled us to pin-point the tarpon's location to within a few square kilometers of the upper St. Lucie River for the period from 17 to 25 October (Fig. 7b).

At present the wet/dry sensor is only good for detecting salinities $<10$ psu (error $<1 \mathrm{psu}$ ). Therefore, in its present configuration, the tag's salinity detection may not be useful for pelagic species such as billfish and tuna, where salinity changes are on the order of $10^{-3}$ psu. On the other hand, it is suitable for species like tarpon that are known to frequently move between oceanic, coastal bay and riverine environments (Robins \& Ray 1986, Ault et al. 2008, Luo et al. 2008). The study of habitat utilization for other coastal marine species, such as sturgeon, snook, manatees, and crocodiles, that are large enough to tag and move between oceanic and freshwater environments, might also benefit from a tag that can provide accurate and precise salinity measurements.

Our salinity results showed a clear tidal cycle that matched the tidal cycle of the upper St. Lucie River (Fig. 8d). Tidal cycle information has also previously been used for estimating geolocations. Hunter et al. $(2003,2004,2006)$ used depth data recorded by demersal fish to determine the tidal phase and compared the tidal database to identify possible geolocations. For non-demersal fish, cyclic salinity phase might be a good candidate for determining tidal phase.

Beside the usefulness in helping geolocation estimation, the salinity measurement derived from the wet/ dry sensor helped us to gain insights into how the tarpon was utilizing estuarine habitats. Our results indicated (Fig. 8d) that the tarpon not only experienced the cyclic tidal fluctuations of salinity change, but was also able to withstand large salinity changes (5 to $35 \mathrm{psu}$ ) in relatively short time intervals (a few hours). This information can help us to determine the BioSalinity Index (BSI; Christensen et al. 1997) of the Atlantic tarpon, and the availability of preferred salinity habitats (Scott 1982, Brown et al. 2000). When combining salinity with temperature data, one might also be able to construct a T/S diagram that could be used to identify the source of water masses (Reid \& Lynn 1971). Of course, this will require a much more highly resolved and accurate salinity measurement by the wet/dry sensor.

The wet/dry sensor was originally designed to automatically determine the wet and/or dry status of the MK10 PAT tag, not as a salinity sensor. When the tag is out of water and dry it records a maximum value of 255. When the tag is in the water and drifting at the ocean's surface the wet/dry sensor is actually out of the water, but waves will keep the float wet, and the sensor will record values between 100 and 255. For example, this was indicated by the WDSV from 18 to 19 November, when the tag was drifting after pop-off, and additionally by some individual spikes during deployment, when the wet/dry sensor was briefly out of the water. This situation could have been the result of 3 possible phenomena: (1) the tag floated to the surface while the tarpon was moving slowly at surface, (2) the tarpon's back came out of the water when the tarpon rolled, or (3) the tarpon jumped clear of the water (Fig. 1b). When the tag is completely underwater, the sensor records values as a continuously increasing function that ranges from 20 to 200 (units) as the conductivity of the water decreases from pure seawater to freshwater, as indicated in our calibration experiment (Fig. 3b). This monotonically increasing function confirmed the usefulness of the sensor as a potential tool for in situ measurements of salinity. The noise associated with the sensor (Fig. 4) most likely results from fluctuations in the internal electronic circuitry, and can be removed with a statistical filter. The differences between individual tags (Fig. 5c) in the calibrations are most likely the result of minor physical differences in tag manufacturing, and are common to all CTD instruments. That is why each CTD instrument has its own calibration parameter file. Therefore, the wet/dry sensor from each MK10 PAT tag should be routinely calibrated before deployment and after deployment, if it has not been damaged and still has battery power.

At present, the resolution and accuracy of the wet/ dry sensors are very poor, especially for salinities $>20$ psu. This mostly resulted from noise levels in the electronics, the 8-bit analog-to-digital conversion scheme and the non-linear nature of the response function. However, both resolution and accuracy of salinity measurements could be improved if a 10-bit or 12-bit analog-to-digital conversion were used instead of the 8-bit conversion scheme. A 10-bit or 12bit scheme would greatly increase resolution (4- or 16 -fold), which means that at 35 psu the resolution would be increased from 8 (8-bit scheme) to 0.5 (12bit scheme) without log transformation, if noise levels could be reduced in the same proportions. In theory, with log transformation, resolution can be increased to $0.01 \mathrm{psu}$ for all salinity levels. Accuracy is dependent on the resolution, stability of tag electronics and rigorous calibration. If the tag electronics were stable, and the calibration done properly, accuracy should be as good as the resolution. We have found that biofouling can be a problem for long-duration deployments, but that is not unique to this device and can be a problem for all instruments in coastal waters. To minimize the bio-fouling, one could shorten the deployment duration or apply an anti-bio-fouling coating on the tag. 
The wet/dry sensor values from the PAT tag are only available when the tag is physically recovered. In 2006 to 2007, with the assistance of a hand-held Argos receiver, we were able to find all 10 PAT tags that had washed up on the beach and were actively transmitting data. From 2001 to 2006 , over $90 \%$ of our PAT tags were washed up to the beach after pop-up (Luo et al. 2007). Therefore, we would expect to find $90 \%$ of the tarpon PAT tags in future studies. For pelagic species such as billfish, tag recovery will continue to be a problem. Of 144 PAT tags deployed on istiophorid billfishes in the Atlantic Ocean, $<10 \%$ were ever recovered (E. D. Prince pers. comm.). Thus, wet/dry sensor data from current MK10 tags are mostly applicable to coastal species.

Despite the shortfalls in salinity measurement by the current generation of wet/dry sensors on the model MK10 PAT tag, the salinity information acquired still greatly helped us to refine the geolocations of this tarpon. Other applications such as habitat utilization (Scott 1982, Brown et al. 2000) and bio-logging (Hooker \& Boyd 2003, Block 2005) are possible when the resolution and accuracy of the sensor are improved. New and smaller conductivity sensor technology is now available (Hyldgård et al. 2005, Li \& Meijer 2005), and soon satellite remote-sensing technology will be able to provide monthly global salinities at a $1^{\circ}$ longitude by $1^{\circ}$ latitude scale, with an accuracy of $0.1 \mathrm{psu}$ (Yueh et al. 2001). Therefore, the challenge to manufacturers is to produce the next generation PAT tags with a high resolution and accurate salinity sensor.

Acknowledgements. This research was supported by funding provided by Bonefish \& Tarpon Unlimited, Sanctuary Friends Foundation of the Florida Keys, National Fish and Wildlife Foundation, and the Florida Fish and Wildlife Conservation Commission. We are grateful for the help and technical assistance of Capt B. Ungar in tag deployment and recovery, and to 3 anonymous reviewers who provided constructive comments that significantly improved this paper.

\section{LITERATURE CITED}

Ault JS, Humston R, Larkin MF, Perusquia E and others (2008) Population dynamics and resource ecology of Atlantic tarpon and bonefish, Chap 16. In: Ault JS (ed) Biology and management of the world tarpon and bonefish fisheries. Taylor and Francis Group, Boca Raton, FL, p 217-258

Block BA (2005) Physiological ecology in the 21st century: advancements in biologging science. Intergr Comp Biol 45:305-320

Block BA, Dewar H, Farwell C, Prince ED (1998a) A new satellite technology for tracking the movements of Atlantic bluefin tuna. Proc Natl Acad Sci USA 95:9384-9389

Block BA, Dewar H, Williams T, Prince ED, Farwell C, Fudge D (1998b) Archival tagging of Atlantic bluefin tuna (Thunnus thynnus thynnus). Mar Technol Soc J 32:37-46

Block BA, Dewar H, Blackwell S, Williams T and others (2001)
Electronic tags reveal migratory movements, depth preferences and thermal biology of Atlantic bluefin tuna. Science 293:1310-1314

Block BA, Teo SLH, Walli A, Boustany A and others (2005) Electronic tagging and population structure of Atlantic bluefin tuna. Nature 434:1121-1127

Boustany AM, Davis SF, Pyle P, Anderson SD, Le Boeuf BJ, Block BA (2002) Satellite tagging: expanded niche for white sharks. Nature 415:35-36

Brown SK, Buja KR, Jury SH, Monaco ME, Nanner A (2000) Habitat suitability index models for eight fish and invertebrate species in Casco and Sheeepscot Bays, Maine. N Am J Fish Manage 20:408-435

Christensen JD, Monaco ME, Lovery TA (1997) An index to assess the sensitivity of Gulf of Mexico species to changes in estuarine salinity regimes. Gulf Res Rep 9:219-229

Domeier ML, Kiefer D, Nasby-Lucas N, Wagschal A, O'Brien F (2004) Tracking Pacific bluefin tuna (Thunnus thynnus orentailis) in the northeastern Pacific with an automated algorithm that estimates latitude by matching sea-surfacetemperature data from satellites with temperature data from tags on fish. Fish Bull Wash DC 103:292-306

Graves JE, Luckhurst BE, Prince ED (2002) An evaluation of pop-up satellite tags for estimating postrelease survival of blue marlin (Makaira nigricans) from a recreational fishery. Fish Bull Wash DC 100:134-142

Hill RD (1994) Theory of geolocation by light levels. In: LeBoeuf BJ, Laws RM (eds) Elephant seals: population ecology, behaviour, and physiology. University of California Press, Berkeley, CA, p 227-236

Hill RD, Braun MJ (2001) Geolocation by light level, the next step: latitude. In: Sibert JR, Nielsen JL (eds) Electronic tagging and tracking in marine fisheries. Kluwer Academic Publisher, Dordrecht, p 315-330

Hooker SK, Boyd IL (2003) Salinity sensors on seals: use of marine predators to carry CTD data loggers. Deep-Sea Res I 50:927-939

Hunter E, Aldridge JN, Metcalfe JD, Arnold GP (2003) Geolocation of free-ranging fish on the European continental shelf as determined from environmental variables. Mar Biol 142:601-609

Hunter E, Metcalfe JD, O'Brien CM, Arnold GP, Reynolds JD (2004) Vertical activity patterns of free-swimming adult plaice in the southern North Sea. Mar Ecol Prog Ser 279:261-273

Hunter E, Berry F, Buckley AA, Stewart C, Metcalfe JD (2006) Seasonal migration of thornback rays and implications for closure management. J Appl Ecol 43:710-720

Hyldgård A, Ólafsdóttir I, Olsesn M, Hedegaard T, Hansen O, Thomsen EV (2005) Fish \& chips: four electrode conductivity/salinity sensors on a silicon multi-sensor chip for fisheries research. Proceeding of IEEE sensors 2005: 1124-1127

Kerstetter DW, Luckhurst BE, Prince ED, Graves JE (2003) Use of pop-up satellite archival tags to demonstrate survival of blue marlin (Makaira nigricans) released from pelagic longline gear. Fish Bull Wash DC 101:939-948

Lewis EL (1980) The practical salinity scale 1978 and its antecedents. IEEE J Ocean Eng 5:3-8

Li X, Meijer GCM (2005) A low-cost and accurate interface for four-electrode conductivity sensors. IEEE Trans Instrum Meas 54:2433-2437

Loefer JK, Sedberry GR, McGovern JC (2005) Vertical movements of a shortfin mako in the western North Atlantic as determined by pop-up satellite tagging. Southeast Nat 4:237-246

Luo J, Prince ED, Goodyear CP, Luckhurst BE, Serafy JE 
(2006) Vertical habitat utilization by large pelagic animals: a quantitative framework and numerical method for use with pop-up satellite tag data. Fish Oceanogr 15:208-229

Luo J, Ault JS, Larkin MF, Humston R, Olson DB (2008) Seasonal migratory patterns and vertical habitat utilization of Atlantic tarpon (Megalops atlanticus) from satellite PAT tags. Chap 18. In: Ault JS (ed) Biology and management of the world tarpon and bonefish fisheries. Taylor \& Francis, Boca Raton, FL, p 275-299

Lutcavage M, Brill R, Skomal G, Chase B, Howey P (1999) Results of pop-up satellite tagging of spawning size class fish in the Gulf of Maine: Do North Atlantic bluefin tuna spawn in the mid-Atlantic? Can J Fish Aquat Sci 56: 173-177

Musyl MK, Brill RW, Curran DS, Gunn JS and others (2001) Ability of archival tags to provide estimates of geographical position based on light intensity. In: Sibert JR, Nielsen JL (eds) Electronic tagging and tracking in marine fisheries. Kluwer Academic Publisher, Dordrecht, p 343-368

Neter J, Kutner MH, Nachtsheim CJ, Wasserman W (1996) Applied linear statistical models. Irwin Press, Chicago, IL

Nielsen A, Bigelow KA, Musyl MK, Sibert JR (2006) Improving light-based geolocation by including sea surface temperature. Fish Oceanogr 15:314-325

$>$ Pearce A, Faskel F, Hyndes G (2006) Nearshore sea temperature variability off Rottnest Island (Western Australia) derived from satellite data. Int J Remote Sens 27: 2503-2518

Prince ED, Goodyear CP (2006) Hypoxia-based habitat compression of tropical pelagic fishes. Fish Oceanogr 15: 451-464

Reid JL, Lynn RJ (1971) On the influence of the Norwegian-Greenland and Wedell Seas upon the bottom waters of the Indian and Pacific Oceans. Deep-Sea Res 18:1063-1088

Editorial responsibility: Kenneth Sherman,

Narragansett, Rhode Island, USA
Robins CR, Ray GC (1986) Atlantic coast fishes. Peterson Field Guide. Houghton Mifflin, Boston, MA

Schaefer KM, Fuller DW (2002) Movements, behavior, and habitat selection of bigeye tuna (Thunnus obesus) in the eastern equatorial Pacific, ascertained through achival tags. Fish Bull Wash DC 100:765-788

Scott JS (1982) Depth, temperature and salinity preferences of common fishes of the Scotian shelf. J Northwest Atl Fish Sci 3:29-39

Sedberry GR, Loefer JK (2001) Satellite telemetry tracking of swordfish, Xiphias gladius, off the eastern United States. Mar Biol 139:355-360

Seitz AC, Weng KC, Boustany AM, Block BA (2002) Behaviour of a sharptail mola in the Gulf of Mexico. J Fish Biol 60:1597-1602

Teo SLH, Boustany A, Blackwell S, Walli A, Weng KC, Block BA (2004) Validation of geolocation estimates based on light level and sea surface temperature from electronic tags. Mar Ecol Prog Ser 283:81-98

Welch DW, Eveson JP (1999) An assessment of light-based geoposition estimates from archival tags. Can J Fish Aquat Sci 56:1317-1327

Welch DW, Eveson JP (2001) Recent progress in estimating geopostion using daylight. In: Sibert JR, Nielsen JL (eds) Electronic tagging and tracking in marine fisheries. Kluwer Academic Publisher, Dordrecht, p 369-383

Wilson RP, Ducamp JJ, Rees WG, Culik BM, Neikamp K (1992) Estimation of location: global coverage using light intensity. In: Priede IG, Swift SM (eds) Wildlife telemetry: remote monitoring and tracking of animals. Ellis Horwood, London, p 131-134

Yueh SH, West R, Wilson WJ, Li FK, Njoku EG, Rahmat-Samii Y (2001) Error sources and feasibility for microwave remote sensing of ocean surface salinity. IEEE Trans Geosci Rem Sens 39:1049-1060

Submitted: February 26, 2007; Accepted: October 11, 2007 Proofs received from author(s): March 11, 2008 